\title{
A SOCIAL HISTORY OF MENTAL HEALTH
}

\section{Sam O’Sullivan}

\section{INTRODUCTION}

Sam's lived experience of struggling with anxiety and professional practice as a clinical psychologist has taken him on a long-term inquiry into what wellbeing looks like. His hospital work has revealed to him the profoundly negative effect that the medicalisation of mental health has had on people because of its focus on individual biology in isolation. A medical intervention is focused on changing a biological mechanism, rather than changing the variety of social and systemic mechanisms also causing the mental health problems.

Through his experience with Tough Talk, an initiative focused on men's mental wellbeing in New Zealand, and associated qualitative research through Capable NZ's Graduate Diploma in Professional Practice (Leadership for Change), Sam has come to understand wellbeing through a social lens. He argues that our wellbeing is depleted by distress related to intangible and powerful social factors, primarily social norms and systems that are harmful for individuals and social groupings we find ourselves in.

\section{WHY PUT EMPHASIS ON SOCIAL FACTORS?}

Most clinicians and academics in the health world would agree that mental health problems are caused by the interplay of biological, psychological, and social factors (Havelka, Lucanin, \& Lucanin, 2009). Although we are seeing a burgeoning interest in the social determinants of mental health, more emphasis appears to have been put on the biological factors; evidenced by the general public's understanding of mental health as a biological illness or chemical imbalance (Choudhry et al., 2016).

It is entirely plausible that any one of the three broad factors named above exerts a stronger influence than others in a given context and time. For example, an individual with brain damage who is experiencing psychosis is likely mentally unwell primarily because of damage to their brain's biological functioning, and secondly because of psychological challenge of coping with the change within a society that views it as weakness. However, when we observed the most recent suicide statistics in the context of Aotearoa, it is clear that social factors are exerting an enormous influence on the mental health of our people and that social factors may be a far higher determinant of mental illness than previously considered :

\begin{tabular}{|l|l|}
\hline \multicolumn{2}{|c|}{ Coroner's report (20 I8): } \\
\hline Deaths by suicide: & 23 per 100,000 \\
\hline Māori: & 13.94 per 100,000 \\
\hline European and other': & 475 \\
\hline Male: & 193 \\
\hline Female & I in 5 have attempted suicide \\
\hline Youth' I2 study (Clark et al., 20 I2): \\
\hline Queer youth & I in 20 have attempted suicide \\
\hline Heterosexual youth
\end{tabular}


Māori are killing themselves at a higher rate than pākehā. It would be dangerous to assume that this is because Māori have biological predisposition to depression. Based on contemporary understanding, it seems highly plausible that depression in Māori communities stems from the trauma of colonisation (Doyle \& Kerrie, 20 I ; Gracey \& King, 2009), the ongoing colonisation through the Western approach to assessment and treatment (Rangihuna, Kopua, \& Tipene-Leach, 20 I 8; Zambas \&Wright, 2016), and the social stressors Māori face as an acculturated group (Saldaina, 1994). Stuber, Meyer, and Link (2008) point out that there are many strong causal links between stigma, prejudice, discrimination and health. It is plausible that the biological mechanism of epigenetics is responsible for historical trauma passing through the generations (Youssef, Lockwood, and Rutten, 20 I8), although the root of the trauma still stems from the violent intersection of two societies which is social in nature.

It would similarly be dangerous to assume that queer youth are attempting suicide more often than heterosexual youth because there is something problematic with their biology. The evidence suggests that their mental health problems are caused by the stress from the everyday prejudice they face as a marginalised group in mainstream society, especially in schools (D'Augelli,, Pilkington, \& Hershberger, 2002).

The higher rate of suicide that males are experiencing in New Zealand is fascinating as it could be assumed that the inherent privileges of being a male in Aotearoa would support the wellbeing of males over females. If we look closer at the statistics, we can see that the ratio is overrepresented by Māori males (Coroner's report, 20 I 8). If we assume that the biological make-up of males is not causing their problems, because in countries such as China the ratio of male to female suicide is more even (World Health Organisation, 20I6), then there must be a social issue to account for this phenomenon.

If the devastating problems we're seeing with suicide in Aotearoa are primarily a social phenomenon, then it seems counterintuitive that our mental health interventions are rarely focused on social change. At the very least we should be educating people that their problems are not merely a fundamental, heritable and immutable part of themselves, which requires medical intervention to repair (e.g., antidepressants for depression and anxiety) (Nutt, 2008).

"Medication may improve the way people are feeling, but also masks the pain manifested in their social context and may inevitably remove motivation from people to drive social change to reduce the true source of their pain." (O'Sullivan, 20 I8)

\section{THE MEDICALISATION OF MENTAL HEALTH}

It is well established that the medicalisation of mental health was driven by economics interests of pharmaceutical companies, and the efficacy of antidepressants medication is placebo at best when all the data is evaluated (Hari, 20 I8; PLOS Medicine Editors, 20I3; Kirsch, 2010). Of course it is important to note that when results are analysed as a whole, important effects on sub-groups can be missed; antidepressants may prove more effective for people when the cause of their mental struggle is more biologically based. A placebo approach to treatment can be considered acceptable if there is little risk of harm, but the use of medication to treat mental health can be physically harmful. It is well known that pharmaceutical medications cause harmful physical side-effects and are only justified because of their efficacy (i.e. the benefit outweighs the harm).

Normal life experiences have also been unnecessarily pathologised. Let's look at the case of over-diagnosis of attention deficit hyperactivity disorder (ADHD). The over-prescription of methylphenidate (aka Ritalin) to children will likely be one of the biggest shams of the 2 I st century. The US Center for Disease Control estimated that 6.4 million children aged 4 to 17 had received an ADHD diagnosis in their lives, which is about I I\% of US children, a $41 \%$ increase from the previous decade (PLOS Medicine Editors, 2013).

The treatment of mental health with medication, driven by an individualistic biological understanding, can also have 
psychological side-effects. Informing someone that their distress is caused primarily by biological dysfunction may leave the person feeling disempowered. It may tell them that their brain, or their very being, is not good enough. If the distress is reduced with medication then it's telling them that the change was caused by an external force (i.e., a pill), rather than supporting the development of an internal locus of control for the change. We know the latter leads to longer term mental health improvement (Karyotaki et al., 20I4). The need for medication to support mental "normalcy" may also lead to people feeling helpless through the reliance of services from health professionals (Mulder, 20।4).

Perhaps the most damaging consequence of this narrative is that it tells people that their distress has no meaning, which may result in people failing to use the pain signals they're receiving as information for useful change.

"Ask not what's inside your head, ask what your head's inside of" (W.M. Mace in Hari, 20 I8)

It should be acknowledged that the medical industry as a whole, particularly practitioners, is deeply motivated to improve people's health. This is not an attack on the medical industry, which is responsible for saving lives every day. Medication helps people with mental health struggles every day. It is of no doubt that there exists a need to explain, or label in some way, what would otherwise be widespread suffering that is challenging to communicate (Mulder, 20I4). The ability to communicate problems efficiently is needed in the current system to gain access to treatment and funding for research (Mulder, 20I4).The specific problem is the public's understanding of the causes of their suffering - they are often making uninformed decisions about treatment and are not participating in social or psychological solutions. The diagnostic labels can also serve as a useful, and somewhat relieving, narrative for someone to understand and explain their problems to others. To give a person in pain a story about why they are hurting is a very powerful thing to do. We need a new story.

"It's not that the way you feel isn't real, it's that it has a different cause than the one you have been told about" (Hari, 20।8).

\section{EARLY INTERVENTION}

Because intervention at the social level is slow, or even completely absent, people's mental health problems often get to the point where a medical intervention is appropriate because they're not in a state where they can adapt to society and create meaningful changes in their lives and challenge the status quo.

By the time someone gets to primary and secondary health care providers, clinicians are generally faced with a person in crisis where it's difficult to treat social and psychological causes (Bracewell-Worrall, 20I8). These providers, such as community mental health teams, are often overwhelmed and only able to focus on the greatest need; moderate to severe presentations (Bracewell-Worrall, 20I8). They're certainly not intervening at an early

stage of the development of a mental health problem, which we've come to understand as critically important time to intervene (Catania et al., 20I I).

At times of crisis and acute mental health presentations medication becomes one of the only feasible approaches, especially in many sterile hospital environments which have not been found to facilitate mental wellbeing (Lawson et al., 2002). We need education in communities to prevent people getting to acute states of mental crisis where they require hospitalization.

Countries like Finland are demonstrating the efficacy of an approach to mental health that focuses on tackling social issues through policy change, making dialogue therapies a first line treatment, and educating their people with mental health skills and literacy (Lehtinen \& Taipale 200I). Aotearoa is behind in this regard and the state of our nations mental health discussed in the recent Mental Health and Addiction review only evidences the need for change (Paterson et al., 2018). 
The way many of us view professionalism in the mental health field may also be systematically disempowering communities to support people at an early stage of their struggles. When a person expresses or show signs of a mental health challenges people supporting them often think "I don't know what l'm doing, I need a professional" (O'Sullivan, 2017). This may be an unintended extension of reasonable public health education, driven by the medical industry, wherein people are discouraged from treating illness or injury without first consulting a medical practitioner (see Ministry of Health guidelines, 20 I8).

An effect appears to occur where people think that involving a mental health professional alone will remedy someone's mental health problem, or at least relieves them from a sense of responsibility (Kirsch, 2009). It's vitally important that people who know and love the person who is suffering are involved in intervention (Dirk et al., 2017). A professional practitioner may be an ideal conduit to facilitate community and wider social intervention, however because western approaches have primarily focused on treating individuals, the majority of practitioners lack the time, mandate, and expertise to do this.

We know that the efficacy of therapy can be largely attributed to the quality of the therapeutic relationship (Martin, Garske, \& Davis, 2000), yet we attempt to seek out distant strangers who are completely removed from the community to be therapists. In fact, the Code of Ethics for Psychologists in Aotearoa (2002) cautions practitioners away from "dual relationships", which can make them anxious about working with people they know personally. We are becoming increasingly isolated in western society (Hari, 20I8). We are socially and systemically repressing non-professional and professional healers who we collectively know and trust in the midst of our communities.

Professional titles are a useful heuristic for determining the quality of knowledge (Esgate et al., 2005), which unfortunately carries the implication that people without titles are not as knowledgeable. It may be the case that unprofessional people in communities are more knowledgeable, but simply lack a professional vocabulary. They also may have more time and local understanding. Marketing has taught us how important it is to communicate knowledge in familiar language (Luna et al., 2003), yet we're stuck on valuing the importance of complex language termed by scientists and people with an interest in selling expensive therapies.

This can be damaging as people who are struggling are not turning to the people around them for support at early stages of their struggles, which means they are instead seeking professionals with long waitlists (Bracewell-Worrall, 2018) or are opting for sometimes unnecessary medical intervention because of the ease of access (Paterson et al., 20 I 8). Ultimately we're not preventing the social and psychological nature of mental health problems at an early stage of their development.

\section{MENTAL HEALTH AS A SOCIAL PROBLEM?}

Hugh Norris (2018) asked: "what do you think is the most important unit to consider in the mental health system?" He believes we overlook the power of our social groupings and put too much emphasis on the individual. The model of illness discussed puts the emphasis on the individual as needing treatment and tends to disregard social influences (Mulder, 2014).

Another view of mental health is that we're experiencing a wide-spread social problem. Let's consider a hypothetical example - the mental health of a woman in the 1950s who by choice, or through societal pressure, works unpaid within the home. She may have been told that she possessed everything a woman could need - a nice husband, a beautiful house, and healthy children. However, she was presenting to her doctor as depressed and didn't understand why. The doctor's typical response at the time would have been that there was something broken within her, which makes sense given the social norms and understanding of mental health at the time. It is now agreed by most people that the social norms of that time were the only thing broken; she may have been feeling distressed because of the way she was conditioned to live, which was preventing her from living a meaningful life. 
Many of us can likely relate to the woman in the 1950s - feeling distressed within ourselves, but not always sure why as we look through the lens of our own conditioning and understanding. A solution may lie in breaking down conditioning and reshaping our social norms in a way that allows people to fully express themselves and be understood.

We now know that wider social beliefs and systems are often implicated in the etiology of mental health problems (Matthews et al., 20 I5). Depression and anxiety may be at least partially caused by the way we are living, which tells a very different narrative - the mental health struggles of an individual is something we are collectively responsible for. This is a much less stigmatizing way to view mental health compared to an illness that affects some people at random or as a product of an individual's choices (Hari, 20 I8). As we increasingly accept a social view of mental health it is fast becoming a political challenge to change the way society works in order to improve health.

"It is no measure of health to be well adjusted to a profoundly sick society" (liddu Krishnamurti)

\section{CASE STUDY:TOUGHTALK}

Tough Talk is a small organisation founded by the author and focused on the mental wellbeing of men in Aotearoa New Zealand, which offers free content to the public: a documentary series and resources/tools for wellbeing (Fig. I).

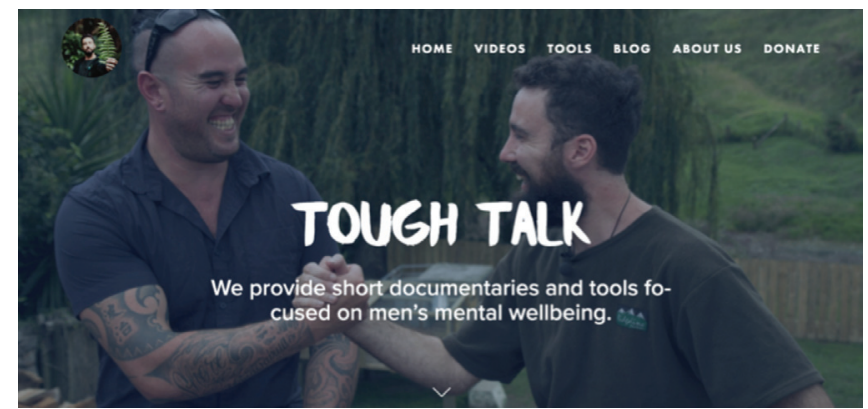

Figure. I:Tough Team website.

Tough talk can be accessed at https://toughtalk.nz/

After observing the disproportionately high rates of male suicide in New Zealand, Sam sought to investigate the social causes of this phenomenon. Extensive qualitative research by the author and two years of traveling, specifically to talk to New Zealanders about the phenomenon, suggests that the roots of this issue resides in the gender identity that has traditionally been ascribed to males: masculinity. It is not claimed that there's anything inherently toxic about masculinity as a whole and it's crucial to realise that every person, regardless of their sex, can identify with masculinity and femininity. The problem seems to lie in certain traits that have been adopted as social norms for masculinity, particularly by males. Namely, not showing vulnerable emotions such as sadness; expressing anger and violence as a sign of strength; not asking for help; an assumption that a male in a heterosexual relationship must provide; pushing for sex; viewing success as out-competing rivals, making lots of money, having an attractive partner based on social norms etc.

These traits can lead to mental health problems through a variety of pathways. For example, Jim loses his job as a builder after injuring his back, which means he can no longer provide for his family in the way that he is expected to. He feels sad and fearful about the future, but expresses his feelings as anger towards his family because it's the only way he knows how to feel. His partner leaves him. He feels like a complete failure as a man and assumes she left him because he can no longer work. He doesn't tell anyone about his intense distress, starts drinking, spirals into worsening mental health, and eventually comes to feel is only open is suicide, even though there were many intervention points where Jim's pathway could have been changed. 
Another pathway for Jim may have involved medical intervention. For example, imagine that he sought out his General Practitioner at the time when he was starting to take out his emotions on his family. After completing a tick list he is told he has moderate depression and is offered antidepressants. Jim worries that he has something wrong with his brain, so begins taking the pills. He starts to feel better after a few weeks, but begins putting on weight and losing his libido. His wife feels less attracted to him, but he doesn't seem to notice. Jim doesn't feel any motivation to find a new job or meaningful occupation. Eventually he starts to feel depressed again and this time his wife leaves him. He ups his medication and lives alone in an apartment on the benefit watching television.

Tough Talks seeks to challenge problematic aspects of the social norm of masculinity and reshape the construct within our collective psyche by normalising men being vulnerable. If men feel confident to voice their internal suffering then they will be able to seek help.

The documentary series shows a diverse range of Kiwi men telling their stories of facing challenges and getting through them because they learnt that it was ok to show vulnerable emotions.

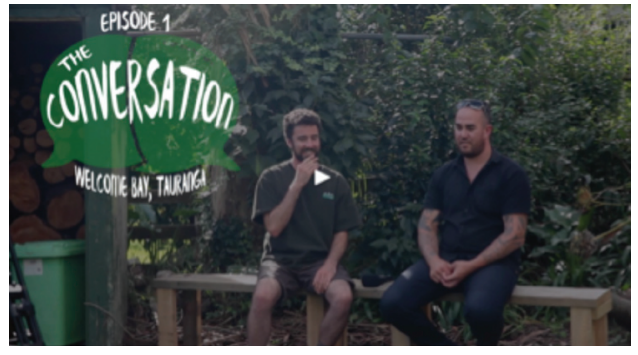

"It wasn't a go with the flow soft man and it wasn't this macho tough guy. It was finding the space in between. Where I can be dependable, I can be solid, I can be funny. And also be gentle and delicate as well" (Matiu te Huki, Musician).

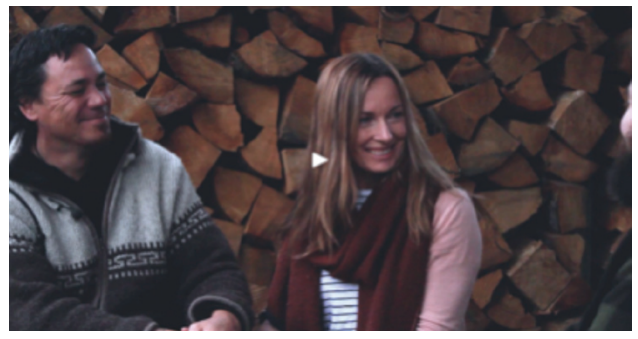

"It was either suicide or look for help, those were my two options, and I went looking for help" (Matt Brown, Barber)
"Talk about it as much as you can. Get it out there, be a man. Don't be a sookie - you know like 'harden up', that's being a sookie. Be a man and talk about it and feel your feelings" (Adam Sharplin, Hunter).

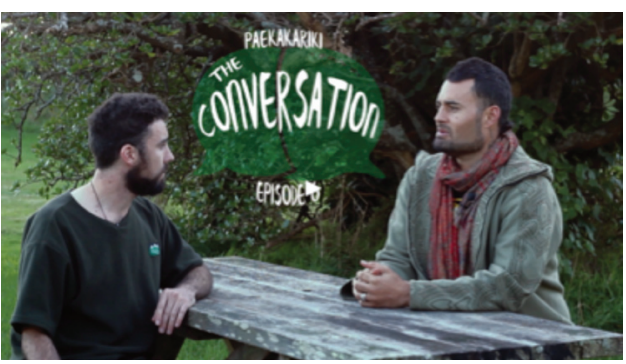

"Challenge your behaviours. Break the cycle, don't perpetuate the cycle. Have the courage to change" (Michael Walker, ex Navy)

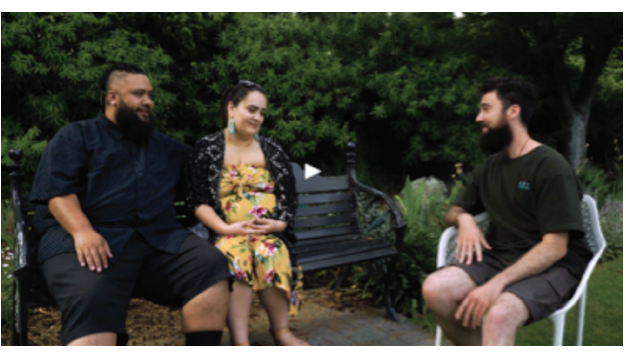


Tough Talk reshapes the way we view toughness through their realisations that it takes incredible strength to talk about our hidden fears and suffering. It showcases the internal tools that have worked for people personally and for supporting others. Often Kiwi males are incredibly motivated by helping others - by teaching tools to help others they receive the benefits too. Tough Talk has been telling a new story of being a man - a story where people still embody positive qualities of masculinity like courage, while empowering and equipping communities with tools to support the people around them. It exemplifies an intervention that is reshaping a specific social norm that is problematic.

In this new story Jim still loses his job, but he talks to his family and mates about how he is feeling. They support and encourage him to take up wood carving and explore playing the guitar. It takes him a while to come to terms with the change, he goes through a rough patch at one point and has a few reckless nights drinking, but he always lets others know how he is feeling. He learns to accept what happened. His family love having him around more and his relationship with his partner deepens. He realises how lucky he was to have a supportive family and starts to help the people around him with the tools and wisdom he had been learning.

\section{CONCLUSION}

The way that we are perceiving mental health is changing from a phenomenon manifested within the biology of individuals, to a social phenomena present in the relationships and understanding within and between groups of individuals. Our interventions need to catch up with this understanding, especially if we are to intervene early enough to improve our success rates. Medication may improve the way people are feeling, but also masks the pain manifested in their social context and may inevitably remove motivation from people to drive social change to reduce the true source of their pain. As we grasp this new perception of mental health, there are profound implications for the ways we can intervene. The solutions may lie in reweaving our social fabric - our policies, economy, organisational systems, and shared beliefs about who we are and our purpose on this planet.

Please note:The information here is not designed to replace individual medical advice from your health professional - please do not stop or reduce medication without consulting with them first.

Sam O'Sullivan is a Clinical Psychologist, facilitator, mindfulness practitioner, and positive activist. He founded Tough Talk, a campaign focused on men's mental wellbeing, and is an integral part of Tuia Learning Environment. He is focused on changing the way many people think about wellbeing from an individualistic experience to a phenomenon that exists in the relationships between people and the environment. Sam is involved in developing new technology to support people's access to wellbeing support and speaks at various events around Aotearoa about the importance of breaking down our conditioning so we can all collaborate towards a flourishing future.

I 'European and other' includes, but is not limited to: New Zealand European, European, Middle Eastern, Latin American, African and 'not elsewhere defined'. 


\section{REFERENCES}

Bracewell-Worrall, A. $(2018,09,18)$. Young people waiting months for mental health appointments, Newshub. Retrieved from https:// www.newshub.co.nz/home/politics/2018/09/young-people-waiting-months-for-mental-health-appointments.html

Catania, S., Purcell, R., \& Newman, L. (20I I). Prevention and early intervention for mental health problems in 0-25 year olds: Are there evidence-based models of care? Advances in Mental Health, 10(1): 3-16.

Choudhry, F. R., Mani, V., Ming, L. C., \& Khan, T. M. (2016). Beliefs and perception about mental health issues: a meta-synthesis. Neuropsychiatric disease and treatment, 12, 2807-28 I8. doi:I0.2147/NDT.SI I I 543

Coroner's report (2018). Chief Coroner releases provisional annual suicide figures. https://coronialservices.justice.govt.nz/assets/ Documents/Publications/20180824- Provisional-suicide-statistics-2017-I8-media-release.pdf

Cosgrove L, Krimsky S (2012) A Comparison of DSM-IV and DSM-5 Panel Members' Financial Associations with Industry: A Pernicious Problem Persists. PLoS Med 9 3: el 001190 doi: I 0.137//journal.pmed. I00 190

Clark, T. C., Fleming, T., Bullen, P., Denny, S., Crengle, S., Dyson, B., Fortune, S., Lucassen, M., Peiris-John, R., Robinson, E., Rossen, F., Sheridan, J., Teevale, T., Utter, J. (2013). Youth'I2 Overview: The health and wellbeing of New Zealand secondary school students in 2012. Auckland, New Zealand:The University of Auckland.

D'Augelli, A., Pilkington, M., \& Hershberger, S (2002). Incidence and Mental Health Impact of Sexual Orientation Victimization of Lesbian, Gay, and Bisexual Youths in High School. School Psychology Quarterly, Vol. 17(2).

Dirik A, Sandhu S, Giacco D, et al Why involve families in acute mental healthcare? A collaborative conceptual review BMJ Open 2017;7:e017680. doi: 10.1136/bmjopen-2017-017680

Doyle, Kerrie (20 I I). Modes of Colonisation and Patterns of Contemporary Mental Health:Towards an Understanding of Canadian Aboriginal, Australian Aboriginal and Maori Peoples. Aboriginal and Islander Health Worker Journal, 35 ( I), 20-23. Availability.

Esgate, A., Groome, D. (2005). An Introduction to Applied Cognitive Psychology. Psychology Press. p. 201.

Fredrickson, B \& Losada, M. (2005). Positive affect and complex dynamics of human flourishing. American Psychologist. 60 (7): 678-686. doi: 10.1037/0003-066x.60.7.678

Gracey M, King M. (2009). Indigenous health part I: determinants and disease patterns. Lancet; 374: 65-75.

Hari, J. (20 18). Lost connections: Uncovering the real causes of depression- and the unexpected solutions. New York, NY, Bloomsbury.

Havelka, M., Lucanin, J., \& Lucanin D. (2009). Biopsychosocial model - the integrated approach to health and disease. College Anthroplogy, 33(1), 303-310.

Healy, David. (2003). The Antidepressant Era. Cambridge, Massachusetts, Harvard University Press,

Luna, D., Peracchio, L.A., \& de Juan, M.D. (2003). The Impact of Language and Congruity on Persuasion in Multicultural E-Marketing. Journal of Consumer Psychology, I 3(I-2), 4 I-50.

Martin, D.J, Garske, J.P, \& Davis, M.K. (2000). Relation of the therapeutic alliance with outcome and other variables: a meta-analytic review. Journal of Consultant Clinical Psychology, 68(3), 438-50.

Matthews, C.J., Jacobs, C.N., Narayanasamy, K., \& Hardani, A. (2015). The Effect of Western Psychiatric Models of Mental IIIness on a Non - Western Culture. Journal of Social Science Research, 3(2), 2327-55 10.

Ministry of Health. (20/8). Retrieved from https://www.health.govt.nz/:

Karyotaki et al. (2014). The long-term efficacy of psychotherapy, alone or in combination with antidepressants, in the treatment of adult major depression. Good Clinical Practice (GCP) Brussels: Belgian Health Care Knowledge Centre (KCE). KCE Reports 230. $\mathrm{D} / 2014 / 10.273 / 72$.

Kirsch, I. (20I0). The emperor's new drugs: Exploding the antidepressant myth. New York, NY: ReadHowYouWant.

Lawson, B., \& John, W. (2002). The effect of the hospital environment on the patient experience and health outcomes. The Journal of Healthcare Design and Development, 27-32

Lehtinen, V., \& Taipale, V. (200 I). Integrating mental health services: The Finnish experience. International journal of integrated care, I: 26.

Mulder, R.T. (2014). Unmet need or medicalising distress? The NZ Medical Journal, I27, I399.

Norris, $\mathrm{H}$ (20।8). Skype interview with former Director of Strategy, Advocacy, and Research for the Mental Health Foundation of NZ.

Nutt, D. (2008). Relationship of neurotransmitters to the symptoms of major depressive disorder. Journal of Clinical Psychology, 69: 4-7/

O'Sullivan (2016). The Kiwi male psyche: Insights into the wellbeing of Aotearoa New Zealand men. Unpublished report for Mental Health Foundation of New Zealand. 
O'Sullivan (2019). A strategic inquiry into Tough Talk's evolution. Unpublished report as an assignment for a graduate diploma in Leadership for Change, Otago Polytechnic.

Paterson, R., Durie, M., Disley, B., Rangihuna, D., Tiatia-Seath, J., \& Tualamali'l, J.

(20 I). Te Ara Oranga, Report of the Government Inquiry into Mental Health \& Addiction. Retrieved from https://mentalhealth.inquiry. govt.nz/inquiry-report/he-ara-oranga/

PLOS Medicine Editors (20 I3). The paradox of mental health: over-treatment and under-recognition. PLoS medicine, I 0 (5), el 00 I 456.

Rangihuna, D., Kopua, M., \& Tipene-Leach, D (20।8). Mahi a Atua: a pathway forward for Māori mental health. The New Zealand Medical Journal. 131(1471).

Zambas, S \& Wright, J (2016). Impact of colonialism on Māori and Aboriginal healthcare access: a discussion paper, Contemporary Nurse, 52:4, 398-409, DOl: 10.1080/10376178.2016.1195238

Saldaina, D. H. (1994). Acculturative Stress: Minority Status and Distress. Hispanic Journal of Behavioral Sciences, I6(2), I16-128. https://doi.org/l 0.1 I77/07399863940162002

Stuber, J., Meyer, I., \& Link, B. (2008). Stigma, prejudice, discrimination and health. Social science \& medicine (I 982), 67 (3), 35 I-357. doi: 10.10 | 6/j.socscimed.2008.03.023

World Health Organisation (2016): https://www.who.int/gho/mental_health/suicide_rates_male_female/en/?fbclid=IwAR0GOi57g k I kliQmD0LpksRf5Irlc5y8v2b ITpKv3cNWB4Us I YD9WwrS4Ak

Youssef, N. A., Lockwood, L., Su, S., Hao, G., \& Rutten, B. (20I 8). The Effects of Trauma, with or without PTSD, on the Transgenerational DNA Methylation Alterations in Human Offsprings. Brain sciences, 8(5), 83. doi: I 0.3390/brainsci8050083. 